\title{
A SARRACENIA PURPUREA POPULATION IN A PEATLAND OF SOUTHERN NEW HAMPSHIRE
}

MARC SudMAN • 3557 Michigan Avenue • Cincinnati, OH 45208 • USA • sarracenia@ mlsuds.com

Keywords: Observations: New Hampshire, Sarracenia purpurea.

To him who works and seeks in her, Science gives much pleasure-to him who learns her facts, very little... a higher culture must give man a double brain, two brain-chambers, so to speak, one to feel science and the other to feel nonscience, which can lie side by side, without confusion, divisible, exclusive; this is a necessity of health.

\section{-Friedrich Nietzsche, Human, All Too Human}

\section{Introduction}

This paper presents some summary comments on a previously uninvestigated Sarracenia purpurea population of 134 plants. While these data are "old", from studies I undertook in 1999 as part of a New England College Peatland Research Project, the information has not before been published.

Instead of publishing the information as a rigorous scientific review, I want to provide the reader of Carnivorous Plant Newsletter a qualitative taste of the work I did. The interested reader is encouraged to dig into the details of my data and a portfolio of about thirty images documenting the site, by visiting my web site: http://sarracenia.mlsuds.com. My research included observations of the plants and the inquiline community, and how they were affected by the changing seasons. A supplemental paper, also available online, explores the beginnings of an investigation into resource parasitism by Linyphiid spiders in response to morphological correlates of prey capture rates in pitchers of this population of $S$. purpurea.

The population of plants inhabits a small peatland consisting of a floating sphagnum mat (dominated by Sphagnum magellanicum) surrounded by a small moat. Preliminary hydrogeological investigations indicate that this site is an oligotrophic, level, quaking peatland. Indicator species of both fen and bog compositions are present so it might be said that this peatland is a poor fen (but for those who enjoy the colloquial term bog, this site can then be called bog-like). There is no open water, although in some areas of the peatland the moat can extend considerably onto the mat causing seasonally fluctuating standing water. The sphagnum mat is dominated by Ericaceous plants (Kalmia polifolia, K. angustifolia, Andromeda glaucophylla, Chamaedaphne calyculata, Vaccinium macrocarpon) with occasional eastern white pine (Pinus strobus), tawny cotton grass (Eriophorum virginicum), and sparsely distributed sedges (Carex spp.). Ericaceous cover is highly variable throughout the site; some parts of the mat consist of a considerable ericacious root system, while other spots consist of only Sphagnum. The Sarracenia inhabit about 1/3 the area of the quaking mat, and are distributed in patches.

\section{Monitoring}

For over a year leading up to this monitoring, I spearheaded a research endeavor to explore the biological and environmental systems present at his bog. Starting on 17 May 1999, I made daily visits to the site until 10 June. I first tagged 83 Sarracenia colonies (or clumps) with numbered aluminum dog tags. The colonies were marked with a bamboo pole $50 \mathrm{~cm}$ high, with a bit of pink flagging attached at the top. Some characteristics I measured are described below. Again, I encourage interested researchers to review the data and tables online.

1) Number of plants per clump. Because it is difficult to determine the number of plants based on pitcher number and orientation, several methods were used to determine number of plants per tag. Some colonies were explored by gently moving sphagnum out of the way and observing or feeling 


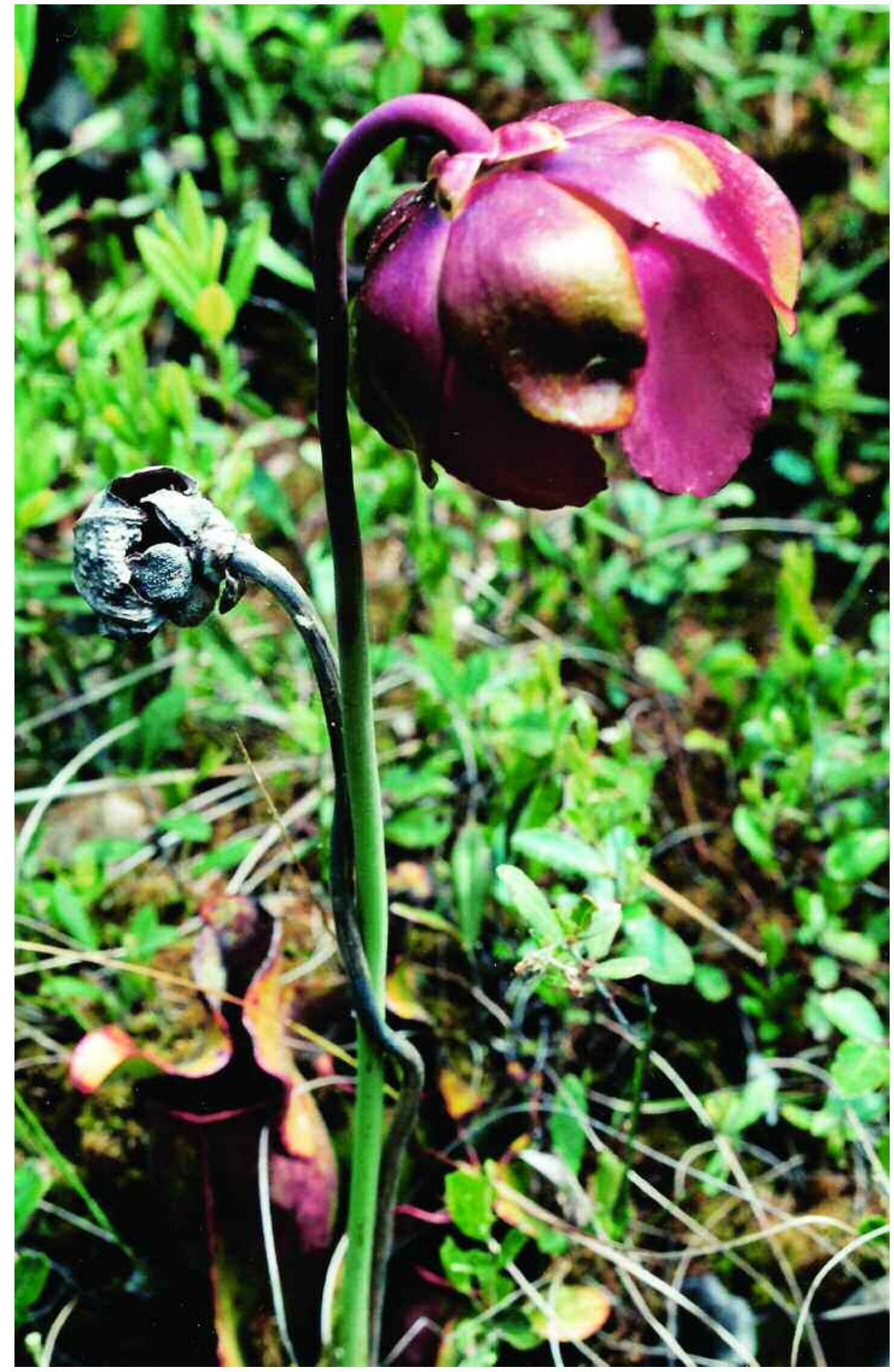

Figure 1: Sarracenia purpurea flowering in New Hampshire. 
for root apices. At colonies with more than one inflorescence (both present year's and last year's), the number of inflorescences was used as an indication of number of plants.

2) Number of pitchers per clump. This was counted and a determination was made on the number of actively trapping pitchers. Those pitchers that were filled with water to about half the pitcher volume were counted as actively trapping pitchers. The remaining pitchers were either chewed upon, drained of water, buried in the sphagnum, or moribund. Although the title "actively trapping pitchers" suggests that the plant is producing nectar and/or utilizing prey nutrients, the term is used here primarily to distinguish healthy pitchers from dead or dying pitchers and possibly to determine age of pitchers.

3) Inflorescence characters. Traits such as inflorescence height, bud production, flower orientation (i.e. nodding vs. upright), and other developmental stages were noted over the season (see Figure 1).

4) Pitcher growth. I noted new pitchers as they developed. I made my observations being as noninvasive as possible, so the plants would not be disturbed by my monitoring work. I also documented the production of abnormal flat leaves, which do not function as pitchers.

5) The entire population was mapped, and location-specific data $\mathrm{pH}$ and temperature data were collected.

Because of the extensive effort in identifying each plant by tag, plant specific data collection, and mapping the exact location of each plant/tag, any subsequent visits and studies will provide great insight into the developmental changes to this $S$. purpurea population.

\section{Anecdotal Observations}

I have included some of those words from my field notebook that offer description in a way no data can. The following words are as scribbled in my pad, with only minor editing for clarity and brevity. Some of the following passages/notes describe the flora and fauna contained in the above sections and the work associated with producing these data; some do nothing but describe. I expect that those who have worked on field projects will recognize the spirit of many of these thoughts and observations, while those who have not experienced the mixed pleasures and frustrations of fieldwork will gain some insight into this difficult kind of work. More of my comments are visible at my web site.

17 May/99 9:30

-Ahhhhh...! The weather's fine for my 1st day at this project....Now I begin the field work. I expected to find, and still do expect to find, great distances between the earlier paper submitted \& what will go on in the field.... Today I visited each plant with a tag (almost all). They don't look so good. There are many pitchers that appear to have been chewed upon, both the hood and holes in the pitcher. Many pitchers are entirely dead (moribund/brown) and many contain no water. 1st year (new) pitchers are just beginning to show form.... The inflorescence buds are noticeable as ca. $1.5 \mathrm{~cm}$ balls extending maybe 2-3 inches from the base. Several plants have inf. buds at their base but the buds have been removed. I need to study growth stages and the development of the plant's anatomy.

\section{May/99 9:30}

-I've renumbered the plants so that I can produce a more logical map. I still have several plants to tag and still others to flag. All data and plant \# will be coordinated when all tagging, flagging, locating and switching is finished. I noticed an incredible \# of Bowl \&Doily (Ed.- -spiders from genus Neriene) webs in the top/end of Ericacious branches. Most of the B\&Ds were occupied by 2 spiders. They were all over near pitcher plant \#14 area. 
-I've noticed that many of the inflorescence buds are either removed from the plant entirely or moribund. Many of the buds are found sitting on the sphagnum as though they were carefully removed from the peduncle. Many of the peduncles are seemingly wilted or broken at a joint/bend. So far, all of the buds/infl. found removed from the plant are ca. 1.0-1.5-2.0 cm across.

- The flower buds are variable in size. Plant \#9 seems to have the largest flowering buds at this time. Some are still only several $\mathrm{cm}$. extended above the root apex while some are $>10 \mathrm{~cm}$.

\section{May/99 900}

-I noticed many Wyeomia adults in several pitchers. They appeared dead on the surface of the water or flailing about on surface.

-On a pitcher at plant \#34 I witnessed a nice visit by a housefly. It landed on the top of the hood and proceeded to explore the pitcher. It traveled down on to zone 1 and methodically traversed the zone. It explored the entire zone tracing several paths. It teetered on the boundary between zones $1 \& 2$. I waited for it to lose its grip on zone $2 \&$ slip into the water, which was ca. $1 \mathrm{~cm}$ below zone. It didn't! It made its way onto the nectar roll \& explored the surface. I could see its proboscis moving erratically over the surface of the pitcher. It repeated this venture, not in any pattern though, for ca. 5 minutes until a beetle (same as collected on 25 May/99) landed/crawled onto zone 1. The fly then flew to another pitcher on plant \#33. I thought I'd witness a trap/capture!...

-new growth is variable in size from plant to plant. Could it be related to microhabitat?!?!

-more dead inflorescences

\section{Jun/99 830}

It's likely to rain today. I feel comfortable in the bog when it's raining. Last time it rained while I was there, I climbed up a fallen pine that was resting on limbs from upright pines/oaks. It made for a nice slanted platform to make my way up toward the higher "ground." Once I had climbed ca. 15 feet above the sphagnous mat, I reclined on the fallen tree trunk and rested there for maybe half an hour. Today, this morning, was beautiful. The sky opened up \& sunshine made its presence. It was hot but was much welcomed! It was humid, it was hot, the mosquitoes \& flies \& spiders were out in full force, the mat was close to saturated. . that's how i like in the bog - Alive!!!

\section{Jun/99}

-Sitting over pitcher plant \#5, I could witness many visits to the pitcher by Culicids. These are presumably the same sp. as the one collected on $7 \mathrm{Jun} / 99$. These small creatures hover in \& out of pitcher openings. Some I've seen land \& remain still on zone $1 \&$ others, those brave souls, actually wander to zone $2 \& 3$ if the water level permits. I have spent much time witnessing these visits; not once have I seen a "trap" although I observe dead ones all the time floating on the surface of its grave. Is Kalmia angustifolia flowering early?

Acknowledgments: Dr. Michael Wirth-thank you! I would also like to thank Barry Rice of The International Carnivorous Plant Society for his assistance in preparing this submission.

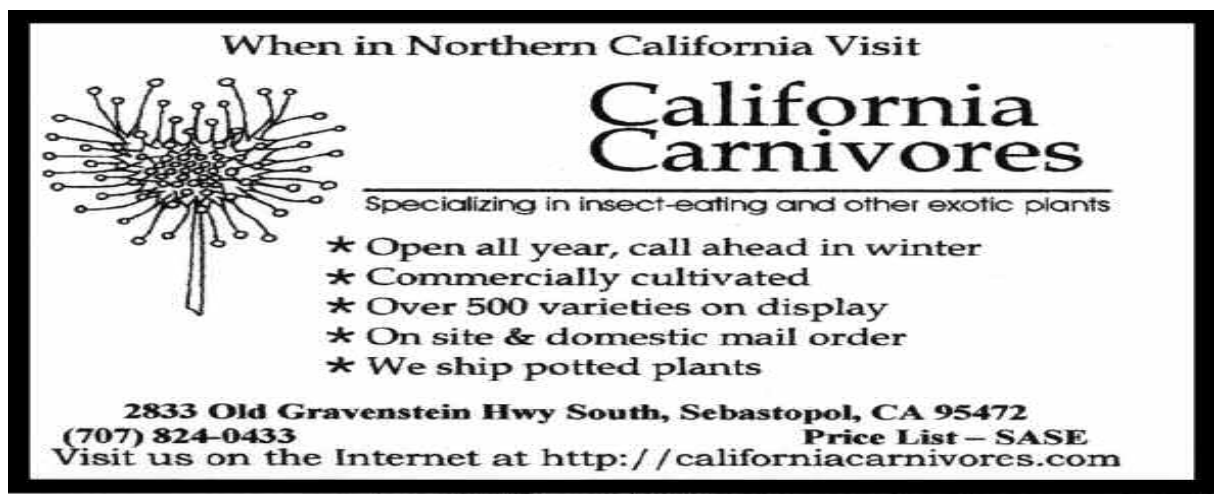

